\title{
Anafilaxia periparto recorrente como manifestação de mastocitose sistémica
}

\section{Recurrent peripartum anaphylaxis as a manifestation of systemic mastocytosis}

Data de receção / Received in: 20/1 1/2019

Data de aceitação / Accepted for publication in: 31/01/2020

Rev Port Imunoalergologia 2020;28 (4): 24I-246

Ana Luísa Moura', Frederico Regateiro ${ }^{1,2,3}$, Iolanda Alen Coutinho', Diana Santos Mota ${ }^{4}$, Artur Paiva ${ }^{5}$, Ana Todo Bom ${ }^{1,6}$, Emília Faria'

I Serviço de Imunoalergologia, Centro Hospitalar e Universitário de Coimbra

2 Instituto de Imunologia, Faculdade de Medicina, Universidade de Coimbra, Coimbra

${ }^{3}$ Instituto de Investigação Clínica e Biomédica de Coimbra (iCBR), Faculdade de Medicina, Universidade de Coimbra

${ }^{4}$ Serviço de Hematologia, Centro Hospitalar e Universitário de Coimbra

${ }^{5}$ Unidade de Gestão Operacional em Citometria, Serviço de Patologia Clínica, Centro Hospitalar e Universitário de Coimbra

${ }^{6}$ Faculdade de Medicina, Universidade de Coimbra

\section{RESUMO}

A mastocitose é uma doença rara com elevado risco para reações anafiláticas graves. Descrição do caso: Mulher que, aos 27 anos, desenvolveu choque anafilático durante um parto por cesariana. No perioperatório foram administrados lidocaína, ropivacaína, ocitocina, cefazolina e fentanilo. Os testes cutâneos foram positivos apenas à ocitocina (leitura imediata). Um ano mais tarde surgiram lesões cutâneas maculopapulares, vermelho-acastanhadas, pruriginosas, no tronco e membros inferiores, com sinal de Darier. A biópsia cutânea foi sugestiva de mastocitose. Em cesariana subsequente, ocorreu novo episódio de anafilaxia com paragem cardiorrespiratória e convulsões tónico-clónicas generalizadas. A presença de 3 critérios minor (OMS 2016) permitiu o diagnóstico de mastocitose sistémica: (I) triptase basal 40,I mg/L; (2) mastócitos com morfologia atípica na medula óssea; e (3) expressão aberrante de CD25 nos mastócitos. Conclusão: $O$ diagnóstico de mastocitose exige frequentemente um alto índice de suspeição clínica, nomeadamente em casos de anafilaxia no perioperatório.

Palavras-chave: Anafilaxia perioperatória, choque anafilático, mastocitose sistémica, síndrome de ativação mastocitária. 


\section{ABSTRACT}

Mastocytosis is a rare disease associated with high risk for severe anaphylactic reactions. Case description: Female patient that developed severe anaphylactic shock during a caesarian delivery at 27 years-old. The drugs administered in the perioperative period were lidocaine, ropivacaine, oxytocin, cefazolin and fentanyl. Skin tests were positive only to oxytocin (immediate reaction). One year later, a red-brown, pruriginous, maculopapular rash with Darier's sign was noted in the torso and legs. The skin biopsy showed mast cells in the dermis, consistent with mastocytosis. On a second caesarian section, she had another episode of anaphylaxis with cardiorespiratory failure and generalized convulsions. The diagnosis of systemic mastocytosis was based on following criteria (WHO 20l6): (I) basal serum tryptase levels 40,I mg/L; (2) abnormal morphology of mast cells in bone marrow; and, (3) expression of CD25 on mast cells. Conclusion: The diagnosis of mastocytosis requires high clinical suspicion, particularly in cases of perioperative anaphylaxis.

Keywords: Anaphylactic shock, mast cell activation syndrome, perioperative anaphylaxis, systemic mastocytosis.

\section{INTRODUÇÃO}

A anafilaxia perioperatória é uma reação sistémica grave ocorrida no período perianestésico e uma das causas mais frequentes de anafilaxia na idade adulta $^{\mathrm{l}-4}$. Os fármacos e materiais utilizados nos procedimentos anestésicos e cirúrgicos são potenciais desencadeantes de reações de hipersensibilidade, e a presença de outras variáveis, como comorbilidades associadas, medicação crónica e complicações cirúrgicas podem agravar a reação ou dificultar o seu tratamento ${ }^{3}$.

A mastocitose sistémica (MS) e outras síndromes de ativação mastocitária são fatores de risco para reações de anafilaxia grave no perioperatório ${ }^{5,6}$. A MS é uma doença rara e heterogénea, com uma incidência estimada de I:I50 000, que resulta da proliferação de mastócitos clonais e envolve, frequentemente, a pele e outros órgãos, como medula óssea (MO), fígado, baço e gânglios linfáti$\cos ^{7}$. De acordo com a Organização Mundial de Saúde (OMS), o diagnóstico de MS baseia-se em 5 critérios fundamentais: um critério major - presença de 15 ou mais agregados de mastócitos detetados em secções de MO ou outros tecidos extracutâneos - e quatro critérios minor-(I) presença de mais de $25 \%$ de mastócitos fusiformes/ /com morfologia atípica em secções de MO ou outros órgãos extracutâneos, ou imaturidade/atipia em mais de $25 \%$ dos mastócitos no aspirado medular, (2) mutação pontual ativadora no codão 816 do gene KIT na MO, sangue ou outro órgão extracutâneo, (3) fenótipo aberrante dos mastócitos (CD25 $5^{+}$, com ou sem expressão de $\left.C D 2\right)$, e, (4) nível basal de triptase sérica superior a $20 \mathrm{ng} / \mathrm{mL}^{8,9}$. O diagnóstico de MS é estabelecido pela presença de, pelo menos, um critério major e um minor ou 3 critérios minor 8,9 .

O espetro clínico de MS varia entre quadros assintomáticos e episódios frequentes de sintomas causados pela libertação de mediadores mastocitários, que podem incluir reações anafiláticas fatais ${ }^{9}$. Entre os adultos diagnosticados com diversas formas de mastocitose, a prevalência de anafilaxia situa-se entre $20 \%$ a $56 \%$, o que representa um risco 100 a 1000 vezes superior ao da população em geral ${ }^{3,6}$. Nestes doentes, a hipersensibilidade imediata resulta, habitualmente, da desgranulação de mastócitos desencadeada por fatores inespecíficos (i.e., psicológicos, farmacológicos, mecânicos e alterações da temperatura) ${ }^{6}$. No entanto, reações lgE-mediadas podem também ocorrer ${ }^{3}$. Os fatores desencadeantes mais frequentemente envolvidos nos episódios de anafilaxia associados à MS são as picadas de himenópteros (53\% dos casos), seguidos de reações sem desencadeante identificado (39\%) e, mais raramente, fármacos e alimentos ${ }^{3}$. 
As reações anafiláticas nos doentes com MS são potencialmente graves e, na maior parte dos casos, apresentam-se com manifestações cardiovasculares que incluem síncope com hipotensão arterial ${ }^{3}$.

\section{DESCRIÇÃO DO CASO}

Doente do sexo feminino, atualmente com 39 anos, que, durante um parto por cesariana aos 27 anos num hospital distrital (primeira gravidez), teve um episódio grave de choque anafilático com paragem cardiorrespiratória e necessidade de manobras de reanimação. No período perioperatório foram administrados os seguintes fármacos: lidocaína, ropivacaína, ocitocina, cefazolina e fentanilo.

Foi encaminhada para a consulta de Imunoalergologia tendo sido realizado o seguinte estudo: (I) testes cutâneos de alergia (TCA) com bateria standard de aeroalergénios que foram positivos apenas para $D$. pteronissinus e farinae e negativos para o látex; (2) TCA com cefazolina, ropivacaína, lidocaína e fentanilo, que foram todos negativos nas leituras imediata e tardia; (3) TCA com ocitocina positivos no intradérmico na concentração $0,05 \mathrm{Ul} / \mathrm{mL}$ (foram efetuados testes controlo em cinco doentes atópicos com resultado negativo); (4) provas de provocação (PP) com mepivacaína e ropivacaína negativas; (5) lgE total de $47 \mathrm{UI} / \mathrm{mL}$ e lgE específicas para látex e ocitocina (Phadia, Suécia) negativas. Não foi medida a triptase sérica. Os TCA e PP foram realizados com base nos protocolos definidos pelos grupos Global Allergy and Asthma European Network (GA2LEN@) e European Network on Drug Allergy (ENDA/EAACl), respetivamente para aeroalergénios (+ $L$. destructor) e fármacos.

Foi assumido o diagnóstico de hipersensibilidade à ocitocina como causa da anafilaxia. A PP com o fármaco alternativo (misoprostol) foi negativa. Foi ainda diagnosticada rinite alérgica intermitente ligeira. Teve alta da consulta após ter sido fornecido um relatório com as indicações de eviç̧ões necessárias nos procedimentos futuros.

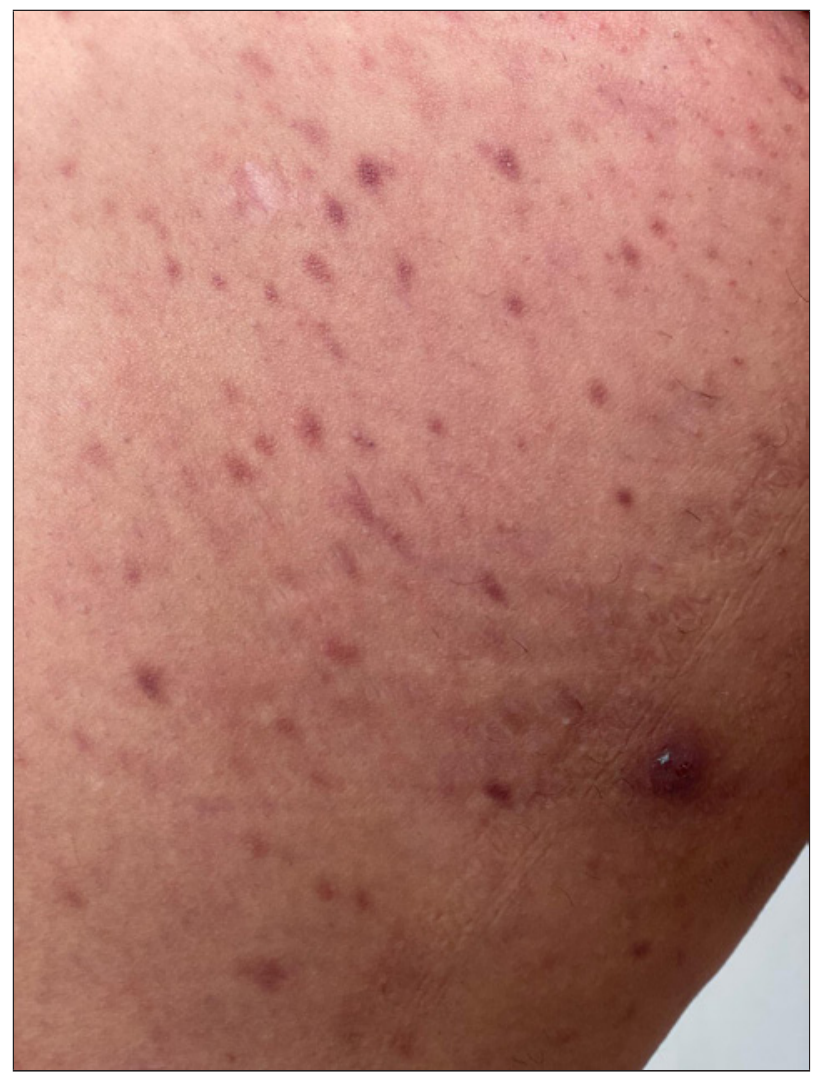

Figura I. Lesões da mastocitose cutânea no membro inferior direito

Cerca de um ano após este episódio de anafilaxia, a doente recorreu a uma consulta de Dermatologia por um exantema maculopapular no tronco e membros inferiores, pruriginoso, com pigmentação vermelho-acastanhado (Figura I), e com positividade na pesquisa do sinal de Darier. Na biópsia cutânea observou-se um infiltrado de mastócitos na derme em número superior a 20 por campo de grande ampliação e de pigmentação basal, sugestiva de mastocitose cutânea maculopapular na variante monomórfica. Foi medicada com anti-histamínico diário.

Quatro anos mais tarde, durante um segundo parto por cesariana, apesar da evicção de ocitocina, a doente desenvolveu novo episódio de choque anafilático grave, com convulsões generalizadas tónico-clónicas e necessidade de medidas de suporte avançado de vida. 
Colocada a hipótese diagnóstica de MS, foi enviada às consultas de Imunoalergologia e Hematologia. Do estudo realizado, a destacar: (I) doseamento da triptase sérica basal 40,1 e 39,2 mg/L, em dois momentos distintos; (2) citometria de fluxo do aspirado da MO mostrou $0,09 \%$ de mastócitos, $100 \%$ com fenótipo aberrante-CD25+; (3) medulograma detetou um número aumentado de mastócitos (I\%), sem outras alterações; (4) biópsia medular óssea mostrou presença de células alongadas de citoplasma amplo, evidenciando grânulos metacromáticos, compatível com envolvimento focal da MO por MS; (5) pesquisa da mutação do gene c-KIT D816V em linfócitos e neutrófilos na MO foi negativa, não tendo sido possível a pesquisa nos mastócitos devido ao número diminuído destas células; (6) beta-2-microglobulina sérica normal.

A doença foi classificada como MS indolente, tendo em conta os seguintes aspetos: (I) presença de 3 critérios minor da OMS, (2) ausência de critérios C, (3) ausência de outra neoplasia hematológica associada e (4) ausência de critérios $B^{9}$ (Quadro I).

Mantém vigilância periódica desde essa altura em consultas de Imunoalergologia, Hematologia e Dermatologia. Foram fornecidos planos escritos de emergência e com recomendações para minimizar os riscos em procedimentos futuros (Quadro 2), realizados os ensinos para utilização de dispositivo de adrenalina auto-injetável e emitido o Cartão de Pessoa com Doença Rara, da Direção-Geral da Saúde.

\section{DISCUSSÃO}

Descrevemos um caso raro de uma doente com dois episódios graves de choque anafilático no perioperatório de cesarianas, cuja evolução e investigação etiológica culminaram no diagnóstico de MS, cumprindo três critérios minor da classificação da OMS?.

Quadro I. Critérios da OMS para classificação das formas de mastocitose sistémica

\begin{tabular}{|c|c|}
\hline Critérios & $\begin{array}{l}\text { Presente na } \\
\text { doente descrita }\end{array}$ \\
\hline \multicolumn{2}{|l|}{ Critérios B } \\
\hline $\begin{array}{l}\text { I. }>30 \% \text { de infiltrados de mastócitos (agregados densos, focais) na biópsia de medula óssea e/ou triptase } \\
\text { sérica basal }>20 \mathrm{mg} / \mathrm{L}\end{array}$ & Sim \\
\hline $\begin{array}{l}\text { 2. Sinais de displasia ou mieloproliferação nas linhagens não mastocitária, mas insuficiente para diagnóstico } \\
\text { definitivo de neoplasia hematopoiética com hemograma normal ou ligeiramente alterado }\end{array}$ & Não \\
\hline $\begin{array}{l}\text { 3. Hepatomegalia associada a valores normais de enzimas hepáticas e/ou esplenomegelia palpável sem } \\
\text { hiperesplenismo e/ou linfadenopatia à palpação ou em exame de imagem }\end{array}$ & Não \\
\hline \multicolumn{2}{|l|}{ Critérios C } \\
\hline $\begin{array}{l}\text { I. Disfunção da medula óssea manifestada por } \geq 1 \text { citopenias (leucócitos totais }<1.0 \times 109 / \mathrm{L} \text {, hemoglobina } \\
<10 \mathrm{~g} / \mathrm{dL} \text {, ou plaquetas }<100 \times 109 / \mathrm{L} \text { ), sem neoplasia hematopoiética maligna não mastocitária evidente }\end{array}$ & Não \\
\hline 2. Hepatomegalia palpável associada a valores alterados de enzimas hepáticas e/ou hipertensão portal & Não \\
\hline 3. Envolvimento do esqueleto com lesões osteolíticas e/ou fraturas patológicas & Não \\
\hline 4. Esplenomegalia palpável com hiperesplenismo & Não \\
\hline 5. Malabsorção com perda de peso por presença de infiltrados de mastócitos gastrointestinais & Não \\
\hline
\end{tabular}

Adaptado de Pardanani A. Systemic mastocytosis in adults: 2017 update on diagnosis, risk stratification and management. Am J Hematol 2016;9I(II):1146-59 
Quadro 2. Fármacos associados a maior ou menor risco de reações anafiláticas no perioperatório em doentes com mastocitose

\begin{tabular}{|c|c|c|}
\hline Fármacos & Baixo risco & $\begin{array}{c}\text { Não } \\
\text { recomendados }\end{array}$ \\
\hline Opioides & $\begin{array}{l}\text { Fentanilo } \\
\text { Sulfentanilo } \\
\text { Remifentanilo } \\
\text { Alfentanilo }\end{array}$ & $\begin{array}{l}\text { Morfina } \\
\text { Codeína }\end{array}$ \\
\hline Analgésicos & Paracetamol & \\
\hline Hipnóticos & $\begin{array}{l}\text { Propofol } \\
\text { Etomidato } \\
\text { Cetamina }\end{array}$ & Tiopental \\
\hline Benzodiazepinas & Midazolam & \\
\hline $\begin{array}{l}\text { Gases } \\
\text { halogenados e } \\
\text { óxido nitroso }\end{array}$ & $\begin{array}{l}\text { Desflurano } \\
\text { Isoflurano } \\
\text { Sevoflurano } \\
\text { Óxido nitroso }\end{array}$ & \\
\hline $\begin{array}{l}\text { Agentes } \\
\text { neuromusculares }\end{array}$ & $\begin{array}{l}\text { Pancurónio } \\
\text { Vecurónio } \\
\text { Cisatracúrio }\end{array}$ & $\begin{array}{l}\text { Succinilcolina } \\
\text { Rocurónio } \\
\text { Atracúrio } \\
\text { Mivacurónio }\end{array}$ \\
\hline Anticolinérgicos & Atropina & \\
\hline $\begin{array}{l}\text { Substitutos do } \\
\text { plasma }\end{array}$ & $\begin{array}{l}\text { Cristaloides } \\
\text { Albumina }\end{array}$ & Gelatina \\
\hline Anestésicos locais & Tipo amida & \\
\hline
\end{tabular}

Adaptado de Kumaraswami S et al. Management of a parturient with mast cell activation syndrome: an anesthesiologist's experience. Case Rep Anesthesiol 2018;2018:8920921

Realçamos, por um lado, a primeira manifestação da doença ter sido um episódio de anafilaxia que ocorreu previamente ao aparecimento das lesões cutâneas e, por outro, à gravidez elou cesariana como fatores de stress acrescido nestes doentes.

A evolução silenciosa da doença até a anafilaxia, associada ao diagnóstico de hipersensibilidade lgE-mediada a um dos fármacos administrados no primeiro episódio de anafilaxia, gerou dificuldades no diagnóstico diferencial. Este facto sugere a possibilidade de uma sobreposição de dois mecanismos de reações de hipersensibilidade imediata, alérgico e não alérgico, tendo dificultado a marcha diagnóstica. Para além disso, nesta altura, a medição da triptase sérica ainda não estava disponível neste centro hospitalar.

A erupção cutânea típica, designada por urticária pigmentosa, é a manifestação cutânea mais frequente neste tipo de patologia, ocorrendo em mais de $90 \%$ dos doentes com a forma indolente da doença ${ }^{8}$.

O tratamento da MS é tão heterogéneo quanto as suas diversas apresentações. Nas formas mais ligeiras pode estar indicada apenas vigilância clínica, enquanto nas formas mais graves pode ser necessário transplante alogénico de progenitores hematopoiéticos ${ }^{10}$. No entanto, o tratamento dirigido aos sintomas deve ser considerado em todos os doentes com $\mathrm{MS}^{10}$. Assim, a maior parte dos algoritmos de tratamento abordam (I) a evicção dos desencadeantes das reações, (2) o controlo sintomático com anti-histamínicos, estabilizadores dos mastócitos e modificadores dos leucotrienos e (3) o tratamento emergente das crises, sendo fundamental serem portadores de adrenalina autoinjetável ${ }^{10}$.

A MS indolente, a forma apresentada pela doente que aqui descrevemos, é a forma mais frequente e com prognóstico mais favorável. Existe, no entanto, um risco de reações futuras fatais/perifatais.

O tratamento com omalizumab parece diminuir os episódios em doentes com anafilaxias recorrentes, como evidenciado em estudo recente, onde se verificou que o tratamento com omalizumab reduziu o número e gravidade dos episódios de anafilaxia em 4 de 6 doentes com o diagnóstico de MS indolente ${ }^{10}$.

Tendo em conta o risco de anafilaxia grave devem ser mantidos cuidados durante a anestesia/cirurgia, nomeadamente uma escolha apropriada dos fármacos a serem utilizados no peri-operatório (Quadro 2), a realização de pré-medicação e cuidados gerais de evicção dos possíveis desencadeantes inespecíficos de ativação mastocitária, como controlo da ansiedade e stress emocional, mudanças de temperatura (hipo ou hipertermia), fatores mecânicos (pressão do torniquete e do cuff do medidor de tensão arterial, friç̧ão dos adesivos). 
Ana Luísa Moura, Frederico Regateiro, lolanda Alen Coutinho, Diana Santos Mota, Artur Paiva, Ana Todo Bom, Emília Faria

Salientamos a obrigatoriedade da medição da triptase sérica basal perante uma anafilaxia que, aliado ao despiste de envolvimento sistémico aquando do diagnóstico de mastocitose cutânea, poderia ter evitado/minimizado o segundo episódio de anafilaxia nesta doente.

Este caso clínico ilustra a necessidade de haver um alto índice de suspeição clínica de MS nos casos de reações anafiláticas graves e a necessidade de acompanhamento precoce por equipas multidisciplinares.

\section{Conflito de interesses}

Os autores declaram que não existem conflitos de interesses.

\section{Contacto:}

Ana Luísa Moura

Serviço de Imunoalergologia

Centro Hospitalar e Universitário de Coimbra

E-mail: al-moura@hotmail.com

\section{REFERÊNCIAS}

I. Faria E. Anafilaxia a agentes anestésicos. Rev Port Imunoalergologia 2018;26(4):239-54.

2. Faria E, Rodrigues-Cernadas J, Gaspar A, et al. Drug-induced anaphylaxis survey in Portuguese Allergy Departments. J Investig Allergol Clin Immunol 20I4;24:40-8.
3. Aun MV, Garro LS, Ribeiro MR, Motta AA, Kalil J, Giavina-Bianchi P. Anafilaxia perioperatória: a experiência brasileira. Rev Port Imunoalergologia 2016;24:99-106.

4. Garvey LH, Ebo DG, Mertes PM, Dewachter P, Garcez T, Kopac $\mathrm{P}$, Laguna JJ, et al. An EAACl position paper on the investigation of perioperative immediate hypersensitivity reactions. Allergy 2019;74(10):1872-84.

5. Valent P, Akin C, Bonadonna P, Hartmann K, Brockow K, Niedoszytko $\mathrm{M}$, et al. Proposed diagnostic algorithm for patients with suspected mast cell activation syndrome. J Allergy Clin Immunol Pract 2019;7(4):II25-33.el.

6. Gülen T, Ljung C, Nilsson G, Akin C. Risk factor analysis of anaphylactic reactions in patients with systemic mastocytosis. J Allergy Clin Immunol Pract 2017;5(5):1248-55.

7. Valent P, Akin C, Arock M, Brockow K, Butterfield JH, Carter $M C$, et al. Definitions, criteria and global classification of mast cell disorders with special reference to mast cell activation syndromes: a consensus proposal. Int Arch Allergy Immunol 2012;157:215-25.

8. Hartmann K, Escribano L, Grattan C, Brockow K, Carter MC, Alvarez-Twose I, et al. Cutaneous manifestations in patients with mastocytosis: Consensus report of the European Competence Network on Mastocytosis; the American Academy of Allergy, Asthma \& Immunology; and the European Academy of Allergology and Clinical Immunology. J Allergy Clin Immunol 2016;137(I):35-45.

9. Valent P, Akin C, Metcalfe D. Mastocytosis: 2016 updated WHO classification and novel emerging treatment concepts. Blood 2017; 129(II): 1420-7.

10. Slapnicar C, Trinkaus M, Hicks $L$ and Vadas P. Efficacy of omalizumab in indolent systemic mastocytosis. Case Rep Hematol 2019;2019:3787586. 